\title{
Ibuprofen and Lipoic Acid Conjugate Neuroprotective Activity Is Mediated by Ngb/Akt Intracellular Signaling Pathway in Alzheimer's Disease Rat Model
}

\author{
Susi Zara ${ }^{a}$ Marianna De Collia ${ }^{a}$ Monica Rapino ${ }^{b}$ Stephanie Pacella ${ }^{c}$ \\ Cinzia Nasuti $^{d}$ Piera Sozio $^{a}$ Antonio Di Stefano ${ }^{a}$ Amelia Cataldi ${ }^{a}$ \\ a Dipartimento di Farmacia, Università 'G. d'Annunzio', 'b Istituto di Genetica Molecolare del CNR, Unità di Chieti, e \\ 'Dipartimento di Medicina e Scienze dell'Invecchiamento, Università 'G. d'Annunzio', Chieti, e d'Dipartimento di \\ Medicina Sperimentale e Sanità Pubblica, Università di Camerino, Camerino, Italia
}

\section{Key Words}

Neuroglobin · Akt · Cyclic-nucleotide response

element-binding protein · Apoptosis · Alzheimer's disease

\begin{abstract}
Background: Alzheimer's disease (AD) is a frequent form of senile dementia. Neuroglobin ( $\mathrm{Ngb}$ ) has a neuroprotective role and decreases $A \beta$ peptide levels. Ngb, promoting Akt phosphorylation, activates cell survival involving cyclic-nucleotide response element-binding protein (CREB). A new molecule (IBU-LA) was synthetized and administered to an $A D$ rat model to counteract $A D$ progression. Objective: The aim of this study was to investigate the IBU-LA-mediated induction of Ngb neuroprotective and antiapoptotic activities. Methods: Brain morphology was analyzed through Bielschowsky staining, $A \beta(1-40)$ and $\mathrm{Ngb}$ expression by immunohistochemistry. Akt, p-Akt, CREB and p-CREB expression was evaluated by Western blot, apoptosis through cytochrome C/Apaf 1 immunocomplex formation, and TUNEL analysis. Results: Bielschowsky staining and $A \beta(1-40)$ expression show few nerve connections and $A \beta(1-40)$ expression in an $A \beta$ sample, preserved neuronal cells and $A \beta(1-40)$ expression lowering in an IBU sample, mostly in IBU-LA. The $\mathrm{Ngb}$ level decreases in $A \beta$ samples, compared to control and
\end{abstract}

IBU-LA samples. p-Akt/Akt and p-CREB/CREB ratios reveal a reduction in $A \beta$ sample, going back to the basal level in control and IBU-LA samples. Cytochrome C/Apaf 1 co-immunoprecipitate occurs and TUNEL-positive nuclei percentage decreases in $A \beta$ sample. Probe test performance shows an increased spatial reference memory in the IBU-LA compared to the $A \beta$ sample; no significant differences were seen between the IBU-LA and IBU samples. Conclusion: This evidence reveals that IBU-LA administration has the capability to maintain a high $\mathrm{Ngb}$ level allowing $\mathrm{Ngb}$ to perform a neuroprotective and antiapoptotic role, representing a valid tool in the therapeutic strategy of AD progression.

Copyright $\odot 2013$ S. Karger AG, Basel

\section{Introduction}

Alzheimer's disease (AD) is the most common chronic neurodegenerative disorder which affects people aged 65 years and over, characterized by a progressive decline in cognitive function and learning. Major pathological hallmarks of $\mathrm{AD}$ include extensive neuronal loss, intracellular neurofibrillary tangles and extracellular senile $\beta$-amyloid $(A \beta)$ plaques accumulation within the cerebral cortical and hippocampal regions [1] which can be diag-

\section{KARGER}

Fax +4161306 1234

E-Mail karger@karger.com

www.karger.com
(C) 2013 S. Karger AG, Basel

0304-324X/13/0593-0250\$38.00/0

Accessible online at:

www.karger.com/ger
Susi Zara, PhD

Dipartimento di Farmacia, Università 'G. D’Annunzio'

Via dei Vestini 31, IT-66100 Chieti (Italy)

E-Mail s.zara@unich.it 
nosed only by autopsy [2]. In particular, neurofibrillary tangles are mainly formed by aggregates of hyperphosphorylated microtubular tau protein, whereas the neuritic plaques are complex extracellular lesions in which an $\mathrm{A} \beta$-containing core is surrounded by reactive microglia, fibrillary astrocytes, interleukins and dystrophic neurites [3]. Moreover, $A \beta$ aggregates exert toxic effects on synaptic and cellular functions leading to neurodegeneration, inflammation, and cognitive and neuropsychiatric symptoms [4]. It is well known that the inflammatory process, including superoxide production, together with $\beta$-amyloid deposition, is an important source of oxidative stress in $\mathrm{AD}$ patients [5]. This hypothesis suggests that intracellular and extracellular reactive oxygen species and reactive nitrogen species generated by various mechanisms are the major risk factors that initiate and promote neurodegeneration in idiopathic $\mathrm{AD}$. These observations suggest that the oxidative damage leading to accumulation of DNA errors may be an important factor in the progression of neuronal loss in $\mathrm{AD}$ [2].

Neuroglobin $(\mathrm{Ngb})$ is the third globin expressed in the nervous system [6], and as a member of the globin family, it participates in oxygen homeostasis acting as an endogenous neuroprotector [7]. Previous studies [8] have demonstrated that $\mathrm{Ngb}$ overexpression protects cells from oxidative stress-induced death, indicating that $\mathrm{Ngb}$ possesses a wider neuroprotective role. Ngb levels, in fact, have been found to decrease with age in several rat and human brain regions implying a possible relation between Ngb deficiency and age-related neurodegeneration $[9,10]$. Moreover, a correlation between Ngb expression and $\mathrm{AD}$-induced progression has already been demonstrated in several animals and in in vitro models in which $\mathrm{Ngb}$ overexpression is shown to decrease $A \beta(1-$ $40)$ and $A \beta(1-42)$ levels, improving cognitive performance [11] and decreasing the levels of $A \beta$-induced reactive oxygen species [12]. Furthermore, Ngb directly promotes Akt phosphorylation [13], which in turn activates cell survival pathways by inducing phosphorylation of proteins such as NF-kB, procaspase- 9 and transcription family members such as cyclic-nucleotide response element-binding protein (CREB) [14]. CREB protein is a 43-kDa basic leucine zipper transcription factor involved in numerous cell functions including proliferation, apoptosis, survival, differentiation and adaptive response [15-17].

Multiple studies in different models have extensively stated a critical role for the CAMP signaling pathway and CREB-mediated gene expression in cell survival and also in different forms of synaptic plasticity related to learning
[18], and it is well known that inhibition of the CREBmediated transcriptional program is involved in $A \beta$ induced neuronal derangement and AD progression $[19$, 20].

Current treatment of $\mathrm{AD}$ includes drugs that mainly provide symptomatic, short-term benefits, without affecting the underlying pathogenic mechanisms of the disease [21], though their neuroprotective potential role has also been proposed $[22,23]$ along with the capability to counteract the disease progression.

Starting from this evidence in our laboratory, a new lipophilic molecule, ibuprofen and lipoic acid conjugate (IBU-LA), was synthetized [24] with the aim of counteracting $\mathrm{AD}$ progression by targeting the pathogenic mechanisms of the disease. IBU-LA, in fact, is obtained by joining two molecules, ibuprofen (IBU) and (R)- $\alpha$-lipoic acid (LA), whose beneficial effect in AD has already been demonstrated. IBU, a member of the nonsteroidal anti-inflammatory drugs, seems to protect against the disease development by delaying its onset through an allosteric modulation of $\gamma$-secretase activity, the enzyme that mediates the cleavage of amyloid precursor protein liberating $\mathrm{A} \beta(1-42)$ peptide [25-27], while cycloxygenase-2 inhibition, the principal pharmacological mechanism of IBU, does not seem to be involved in the IBU-mediated Alzheimer beneficial effect [28]. In parallel, IBU has a marginal efficiency in crossing the blood-brain barrier (BBB). On the other hand, LA has been used in trials to prevent $\mathrm{AD}$, based on its antioxidant ameliorating effect on progression of the disease through oxidative stress reduction and brain cholinergic function improvement [29, 30]. IBU-LA, with a high degree of chemical and enzymatic stability, might permit targeted delivery of IBU and LA directly to the neurons, which are stressed in $\mathrm{AD}$ patients. In a previous work, the effects of IBU-LA conjugate in chronic treatment following bilateral intrahippocampal infusion of $A \beta(1-40)$ protein have been reported [31]. The conjugate seemed to protect against the behavioral detriment induced by the simultaneous administration of $A \beta(1-40)$ protein. In particular, spatial cognition, induced by administration of our compound, was more improved than with IBU treatment. This treatment may also protect against the oxidative stress generated by reactive oxygen species and the cognitive dysfunction induced by the intracerebroventricular infusion of $A \beta(1-40)$ in rats.

In order to evaluate the amount of IBU transported across the $\mathrm{BBB}$, its brain concentration after subcutaneous injection of IBU-LA and the parent drug has been previously evaluated [31]. The conjugate exhibited a much higher brain concentration of IBU when compared 
Table 1. Treatment protocol

\begin{tabular}{llllll}
\hline Group & $\begin{array}{l}\mathrm{A} \beta(1-40) \text { infusion } \\
\text { i.c.v. }\end{array}$ & $\begin{array}{l}\text { Vehicle infusion } \\
\text { i.c.v. }\end{array}$ & $\begin{array}{l}\text { Vehicle } \\
\text { s.c. }\end{array}$ & $\begin{array}{l}\text { IBU } \\
\text { s.c. }\end{array}$ & $\begin{array}{l}\text { IBU-LA } \\
\text { s.c. }\end{array}$ \\
\hline Control $(\mathrm{n}=9)$ & - & $200 \mu \mathrm{l} / \mathrm{rat}$ & - & - & - \\
DMSO $(\mathrm{n}=9)$ & - & $200 \mu \mathrm{l} / \mathrm{rat}$ & $\mathrm{X}$ & - & - \\
$\mathrm{A} \beta(\mathrm{n}=8)$ & $200 \mu \mathrm{l} / \mathrm{rat}$ & - & $250 \mu \mathrm{l} / \mathrm{rat}$ & - & - \\
$\mathrm{A} \beta+\mathrm{IBU}(\mathrm{n}=8)$ & $200 \mu \mathrm{l} / \mathrm{rat}$ & - & - & $5 \mathrm{mg} / \mathrm{kg}$ & - \\
$\mathrm{A} \beta+\mathrm{IBU}-\mathrm{LA}(\mathrm{n}=8)$ & $200 \mu \mathrm{l} / \mathrm{rat}$ & - & - & - & $10 \mathrm{mg} / \mathrm{kg}$ \\
\hline
\end{tabular}

Quantity or volume of drug solutions administered to the five groups of rats are represented in $\mathrm{mg}$ or $\mathrm{ml} / \mathrm{kg}$ of rat body weight or $\mu \mathrm{l} /$ rat. $\mathrm{n}=$ Number of rats per group.

with an equimolar dose of IBU alone, suggesting that IBU-LA behaves like a bioreversible bioconjugate and could enhance the availability of IBU in the brain.

Thus, the aim of this study was to investigate the IBULA-mediated potential induction of neuroprotective and antiapoptotic activities of neuroglobin, focusing attention on the molecular events downstream to neuroglobin activation in $A \beta(1-40)$-infused rat brain as a model of AD.

\section{Materials and Methods}

Animals

Male Wistar rats $(\mathrm{n}=42)$ (Harlan, UD, Italy), weighing 200$225 \mathrm{~g}$ at the beginning of the experiments, were used. The animals were housed individually on a 12-hour light/dark cycle (lights off at 7:00 a.m.) at a constant temperature $\left(20-22^{\circ} \mathrm{C}\right)$ and humidity (45-55\%). Rats were offered food pellets (4RF; Mucedola, Settimo Milanese, Italy) and tap water ad libitum. All the procedures were performed according to the European Community Council Directive for Care and Use of Laboratory Animals and in accordance with the Local Ethical Committee.

\section{Drug Preparation}

$\mathrm{A} \beta(1-40)$ peptide (Bachem, Switzerland) was dissolved in sterile saline $35 \%$ acetonitrile $/ 0.1 \%$ trifluoroacetic acid. Both IBU and IBU-LA were solubilized in sterile saline containing $20 \%(\mathrm{v} / \mathrm{v})$ DMSO and administered daily to different animals subcutaneously for 28 days at doses of 5 and $10 \mathrm{mg} / \mathrm{kg}$, respectively. A vehicle solution (vehicle for subcutaneous injections) prepared with sterile saline containing 20\% (v/v) DMSO or a sterile saline alone, were also administered subcutaneously for 28 days at a dose volume of $250 \mu \mathrm{l} / \mathrm{kg}$ as IBU and IBU-LA. One month after the last day of $A \beta(1-40)$ peptide infusion, cognitive and morphological tests were performed.

\section{Surgical Procedure}

The rats were anesthetized with a mixture of zolazepam and tiletamine (10 mg/kg i.p.) (Zoletil 100, Italmed, Italy). Continuous infusion of $A \beta(1-40)$ peptide solution $(4.6 \mathrm{nmol} / \mathrm{rat}$ at a final vol- ume of $200 \mu \mathrm{l}$ ) or the vehicle alone was delivered for 28 days by attachment of an infusion kit connected to an osmotic pump (Alzetmodel 2004, Charles River, Italy). The infusion kit was implanted into the right cerebral ventricle. $A \beta(1-40)$ peptide cerebrospinal infusion and subcutaneous drug treatments were delivered over the same period of time.

The choice of the $A \beta(1-40)$ peptide was dictated by its high affinity to form amyloid fibrils in rats, in which a neurodegenerative effect was evidenced at the CA1 subfield of the hippocampus and by good peptide solubility requirement in order to guarantee a continuous delivery throughout the treatment period. All group treatments are reported in table 1.

\section{Kinetics of Enzymatic Hydrolysis}

The enzymatic hydrolysis of IBU-LA was evaluated in rat plasma at $37^{\circ} \mathrm{C}$. Stock solutions were prepared by dissolving $5 \mathrm{mg}$ of the codrug in $50 \mu \mathrm{l}$ of DMSO. This solution was added to $4 \mathrm{ml}$ of prewarmed $\left(37^{\circ} \mathrm{C}\right)$ plasma previously diluted to $80 \%$ with $50 \mathrm{mM}$ phosphate buffer, $\mathrm{pH}=7.4$, prethermostated at $37^{\circ} \mathrm{C}$. The resulting solution was kept at $37^{\circ} \mathrm{C}$ and $0.2-\mathrm{ml}$ samples were withdrawn at intervals and added to $0.4 \mathrm{ml}$ of cold $\left(4^{\circ} \mathrm{C}\right)$ acetonitrile to precipitate the serum proteins. After centrifugation for $10 \mathrm{~min}$ at $10,000 \mathrm{rpm}$ and at $5^{\circ} \mathrm{C}$, the supernatant was assayed by HPLC

\section{Degradation by Brain Homogenate}

Rat brains were isolated, pooled, homogenized with $20 \mathrm{vol}$ of $50 \mathrm{~mm}$ Tris- $\mathrm{HCl}(\mathrm{pH}=7.4)$, and stored at $-80^{\circ} \mathrm{C}$ until used. The aliquots $(100 \mu \mathrm{l}, 10 \mathrm{mg}$ protein $/ \mathrm{ml})$ were incubated with $100 \mu \mathrm{l}$ of compound $(0.5 \mathrm{mM})$ over $0,7.5,15,22.5,30$ and $60 \mathrm{~min}$ at $37^{\circ} \mathrm{C}$ in a final volume of $200 \mu \mathrm{l}$. The reaction was stopped at the required time by placing the tube on ice and acidifying with $20 \mu \mathrm{l}$ of $1 \mathrm{M}$ aqueous $\mathrm{HCl}$ solution. The aliquots were centrifuged at $20,000 \mathrm{~g}$ for $10 \mathrm{~min}$ at $4^{\circ} \mathrm{C}$. The obtained supernatants were filtered and analyzed by HPLC.

\section{Memory Performance Test}

One month after the last treatment with the drugs, rats were trained for 5 consecutive days in a standard Morris spatial water maze task to learn and remember the spatial location of a platform submerged $1 \mathrm{~cm}$ below the surface of the water in a circular pool $1.5 \mathrm{~m}$ in diameter [32]. Training consisted of 4 trials per day with an intertrial interval of $30 \mathrm{~s}$. On day 6 (i.e. $24 \mathrm{~h}$ following the last hidden platform trial), a probe trial was conducted in which 
the platform was removed from the pool to measure the time spent in the target quadrant where the platform had been located during training for $90 \mathrm{~s}$. The probe test allows assessing the reference memory at the end of learning or memory consolidation that represents a valid measure of hippocampal integrity. Time spent in the target quadrant is expressed as \% time measured in $90 \mathrm{s.}$

\section{Morphological Analysis and Immunohistochemistry}

Excised rat brains, fixed in $10 \%(\mathrm{v} / \mathrm{v})$ phosphate-buffered, paraffin-embedded formalin, were dewaxed (xylene and alcohol in progressively lower concentrations) and stained following the Bielschowsky procedure. In order to detect $A \beta(1-40)$ and neuroglobin, immunohistochemistry was performed using an UltraVision LP Detection System HRP Polymer \& DAB Plus Chromogen kit (Thermo Fisher Scientific, Calif., USA) and processed according to the data sheet. Sections $(5 \mu \mathrm{m})$, performed at the coronal level, were incubated in the presence of rabbit polyclonal antiA $\beta(1-40)$ (Alpha Diagnostics International, San Antonio, Tex., USA) and antineuroglobin primary antibodies (Sigma-Aldrich, St. Louis, Mo., USA) and then in the presence of HRP-conjugated secondary antibody. Peroxidase was developed using diaminobenzidine chromogen. Nuclei were counterstained with hematoxylin. Negative controls were performed by omitting the primary antibodies. The labeled slides were examined with a Leica DM 4000 (Leica Cambridge Ltd., Cambridge, UK) light microscope equipped with a Leica DFC320 videocamera (Leica Cambridge) to acquire computerized images.

\section{TUNEL Analysis}

Terminal deoxynucleotidyl-transferase-mediated dUTP nick end-labeling (TUNEL) is the method of choice for rapid identification and quantification of apoptotic cells. DNA strand breaks, yielded during apoptosis, can be identified by labeling free $3^{\prime}-\mathrm{OH}$ termini with modified nucleotides in an enzymatic reaction. All steps were undertaken with a FragEL DNA fragmentation Detection kit according to the manufacturer's instructions (Calbiochem Merck, Cambridge, Mass., USA). After two rinses in PBS, slides were dehydrated, mounted by using a permanent media and examined under a Leica DM 4000 microscope (Leica Cambridge) equipped with a Leica DFC 320 Videocamera (Leica Cambridge) to acquire and analyze computerized images.

\section{Computerized Morphometry Measurements and Image} Analysis

After digitizing the images, a Leica Qwin 3.5 Plus Software System (Leica Cambridge) was used to evaluate $A \beta(1-40)$ and neuroglobin expression. Image analysis of protein expression was performed through quantification of the thresholded area for immunohistochemical brown colors per field of light microscope observation.

Leica Qwin assessments were logged into Microsoft Excel and processed for percentage, standard deviations and histograms.

\section{Western Blotting Analysis and Immunoprecipitation}

For immunoprecipitation, the cerebral cortex lysate $(500 \mu \mathrm{g})$ was incubated in the presence of $50 \mu \mathrm{l}$ of the suspended IP (Immunoprecipitation) matrix (Exacta Cruz, Santa Cruz Biotechnology Inc., Santa Cruz, Calif., USA) for $30 \mathrm{~min}$ at $4^{\circ} \mathrm{C}$. The matrix was pelleted for $30 \mathrm{~min}$ at $4^{\circ} \mathrm{C}$ and $50 \mu$ of suspended IP matrix,
$3 \mu \mathrm{g}$ of mouse cytochrome $\mathrm{C}$ monoclonal antibody and $500 \mu \mathrm{l}$ of PBS were added to the supernatant and incubated at $4^{\circ} \mathrm{C}$ on a rotator for $1 \mathrm{~h}$. The matrix was then pelleted and washed twice with $500 \mu \mathrm{l}$ of PBS. The cytochrome C antibody-IP matrix complex was incubated with the lysate overnight on a rotator at $4^{\circ} \mathrm{C}$. The matrix containing the immunoprecipitated sample was then pelleted and washed 3 times with RIPA buffer. Samples were boiled and stored at $-80^{\circ} \mathrm{C}$. Cerebral cortex lysates $(20 \mu \mathrm{g})$ or immunoprecipitates were electrophoresed and transferred onto nitrocellulose membranes. Nitrocellulose membranes, blocked in 5\% nonfat milk, $10 \mathrm{mM}$ Tris pH 7.5, $100 \mathrm{mM} \mathrm{NaCl}, 0.1 \%$ Tween-20, were probed with rabbit polyclonal anti-Akt, anti-p-Akt, anti-p-CREB, rabbit monoclonal anti-CREB (Cell Signaling Technology, Danvers, Mass., USA), mouse monoclonal anti-cytochrome $\mathrm{C}$ and rabbit polyclonal anti-Apaf 1 primary antibodies (Santa Cruz Biotechnology) and then incubated in the presence of specific enzyme-conjugated IgG horseradish peroxidase. Immunoreactive bands were detected by ECL detection system (Amersham Int., Buckinghamshire, UK) and analyzed by densitometry. Densitometric values, expressed as integrated optical intensity, were estimated in a CHEMIDOC XRS system by QuantiOne 1-D analysis software (BIORAD, Richmond, Calif., USA). The values obtained were normalized based on the densitometric values of internal $\beta$-actin and $\beta$-tubulin.

\section{Statistics}

Statistical analysis was performed with GraphPad Prism 5 software using ANOVA and the t test. Results are expressed as mean \pm SD. $\mathrm{p}<0.05$ was considered statistically significant.

\section{Results}

In order to verify $\mathrm{AD}$ induction after $\mathrm{A} \beta(1-40)$ infusion, sections were processed for the Bielschowsky procedure which is a marker for nerve connections (fig. 1a) and $A \beta(1-40)$ immunohistochemical analysis (fig. $1 b, c)$. The control sample discloses organized layers of cells, each associated by nerve fiber connections in black, not dilated capillary vessels, while the DMSO sample shows dilated capillary vessels. In $\mathrm{A} \beta$-infused cerebral cortex rare and disorganized neuronal cells along with few nerve connections can be recognizable. The $A \beta+I B U-$ infused cerebral cortex shows few but well-preserved neuronal cells with respect to $A \beta$, while in $A \beta+I B U-L A-$ infused cerebral cortex cells appear well organized and nerve fiber connections seem to be partially restored. In parallel, immunohistochemical analysis of $A \beta(1-40)$ expression was performed revealing that $A \beta(1-40)$ peptide precipitates inside blood vessels. No $\beta$-amyloid expression is evidenced in control and DMSO samples, while the $A \beta$ sample shows a higher $A \beta(1-40)$ expression. $A$ significant decrease of $A \beta(1-40)$ expression is revealed both in the $A \beta+I B U$ - and $A \beta+I B U-L A$-treated samples 


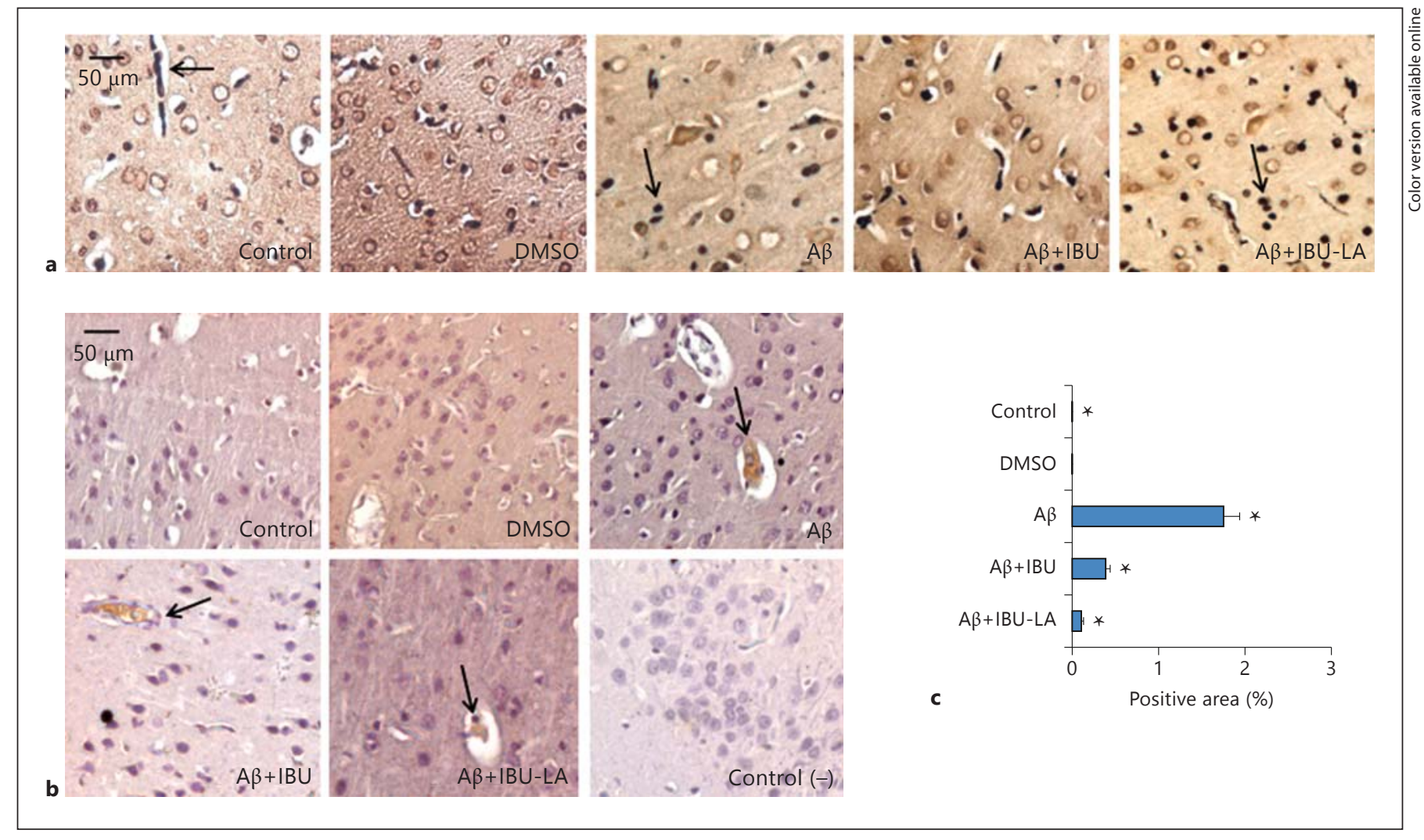

Fig. 1. a Bielschowsky staining of rat cerebral cortex coronal sections in different experimental conditions. Arrows indicate nerve connections (in black). $\times 40$. b Immunohistochemical detection of $\mathrm{A} \beta(1-40)$ peptide (rabbit anti-A $\beta(1-40)$ antibody, Alpha Diagnostic International, San Antonio, Tex., USA, cat. No. BAM403$\mathrm{M})$ expression in rat cerebral cortex in different experimental conditions. Arrows indicate $\mathrm{A} \beta(1-40)$ plaques. $\times 40$. c Densitometric analysis of $A \beta(1-40)$-positive area, expressed as percentage $( \pm S D)$, assessed by direct visual counting of three fields for each of five slides per each sample at $\times 40$ magnification by Leica QWin 3.5 Plus Sotware System. Data are the mean \pm SD of three different consistent experiments. ${ }^{\star} \mathrm{A} \beta$ vs. control; ${ }^{\star} \mathrm{A} \beta+\mathrm{IBU}$ vs. $\mathrm{A} \beta(\mathrm{p}=2.0$ $\left.\times 10^{-8}\right) \mathrm{p}<0.01 ;{ }^{\star} \mathrm{A} \beta+\mathrm{IBU}-\mathrm{LA}$ vs. $\mathrm{A} \beta\left(\mathrm{p}=3.1 \times 10^{-2}\right) \mathrm{p}<0.05$; ${ }^{\star} \mathrm{A} \beta+\mathrm{IBU}-\mathrm{LA}$ vs. $\mathrm{A} \beta+\mathrm{IBU}\left(\mathrm{p}=2.4 \times 10^{-2}\right) \mathrm{p}<0.05$. with respect to $A \beta$ rather than in the $A \beta+I B U-L A$ sample with respect to the $A \beta+I B U$ sample. The expression of $\mathrm{Ngb}$, evaluated through immunohistochemical analysis, is significantly decreased in $A \beta$-infused cerebral cortices with respect to both the control and the $A \beta+\mathrm{IBU}-\mathrm{LA}$ treated samples, while the Ngb level in the A $\beta+$ IBU sample does not show any significant difference with respect to the control and A $\beta+$ IBU-LA-treated samples (fig. 2). In our study, the DMSO sample showed dilated capillary vessels in infused cerebral cortex and should be responsible for the decrease of Ngb expression. In any case, treatment with IBU or IBU-LA was able to restore $\mathrm{Ngb}$ in neuronal cells both in $\mathrm{A} \beta$ - and in DMSO-treated rats. Our observations were restricted to the cerebral cortices since $\mathrm{AD}$ mainly affects these areas, as often reported in the international literature [33]. Since the ability of $\mathrm{Ngb}$ to activate Akt signaling was already demonstrated [13],
Akt expression and activation and the intracellular downstream molecular events were then evaluated. Western blotting analysis shows that Akt expression does not show any significant difference among the different experimental points, while the activated Akt ( $\mathrm{p}$ Akt) and p-Akt/Akt ratio reveals a significantly strong reduction in the $A \beta$-infused sample, going back to the basal level in control and A $\beta+$ IBU-LA-treated samples (fig. 3). Given that CREB is considered a regulatory target for the protein kinase Akt [34], CREB and the phosphorylated/activated form of CREB (p-CREB) were also investigated, revealing for the $\mathrm{p}$-CREB and $\mathrm{p}$-CREB/ CREB ratio a trend parallel to the p/Akt and p-Akt/Akt ratio (fig. 4). Lastly, since $\mathrm{Ngb}$ seems to give protection from intrinsic apoptotic pathway induction, the occurrence of apoptotic events was evaluated through cytochrome C/Apaf 1 immunocomplex formation. Cyto- 


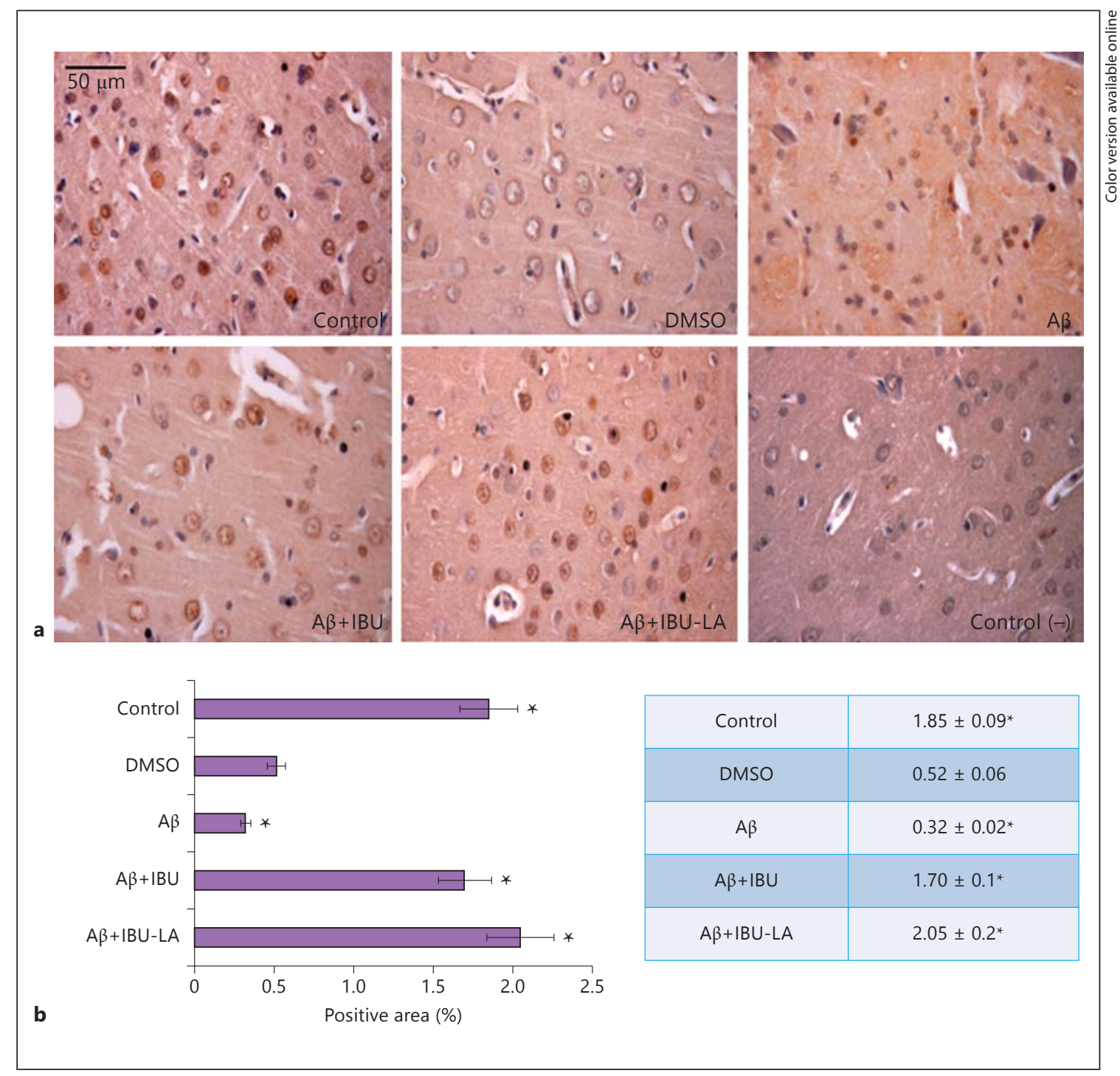

Fig. 2. a Immunohistochemical detection of Ngb (rabbit antineuroglobin antibody, Sigma-Aldrich, cat. No. N7162) expression in rat cerebral cortex in different experimental conditions. The pictures are the most representative out of three consistent experiments. $\times 40$. $\mathbf{b}$ Densitometric analysis of $\mathrm{Ngb}$ expression in rat cerebral cortex coronal sections in different experimental condi-

chrome C/Apaf 1 immunoprecipitation markedly occurs in an $A \beta(1-40)$-infused sample, lowering in the

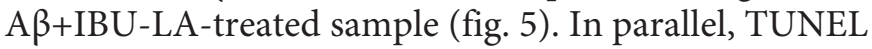
analysis, which evidences DNA strand breaks yielded during apoptosis, shows a positive nuclei percentage decrease at the same experimental point (fig. 6).

All these molecular results are further supported by a probe test performed in a spatial water maze to determine whether or not the animal remembers where the platform

IBU-LA Administration and Ngb Level in $\mathrm{AD}$ tions. Ngb-positive area, expressed as percentage $( \pm S D)$, assessed by direct visual counting of three fields for each of five slides per each sample at $\times 40$ magnification by Leica.Qwin 3.5 Plus Software System. Data are the mean \pm SD of three different consistent experiments. ${ }^{\star} \mathrm{A} \beta$ vs. control $\mathrm{p}<0.01\left(\mathrm{p}=2 \times 10^{-8}\right){ }^{\star}{ }^{\star} \mathrm{A} \beta$ vs. $\mathrm{A} \beta+\mathrm{IBU}-$ LA $\mathrm{p}<0.01\left(\mathrm{p}=3 \times 10^{-4}\right) ;{ }^{\star} \mathrm{A} \beta$ vs. $\mathrm{A} \beta+\mathrm{IBU} \mathrm{p}<0.01\left(\mathrm{p}=5 \times 10^{-4}\right)$.

was located during the training. The group of rats treated with $A \beta(1-40)$ shows a decrease in memory consolidation versus all groups even though no significant differences between $A \beta+I B U-L A-$ and $A \beta+I B U$-infused rat cortices can be observed (fig. 7).

The stability of the new codrug IBU-LA towards peripheral and central enzymatic degradation, by measuring its bioconversion rates in the presence of rat plasma and brain homogenate, was also evaluated, finding that 


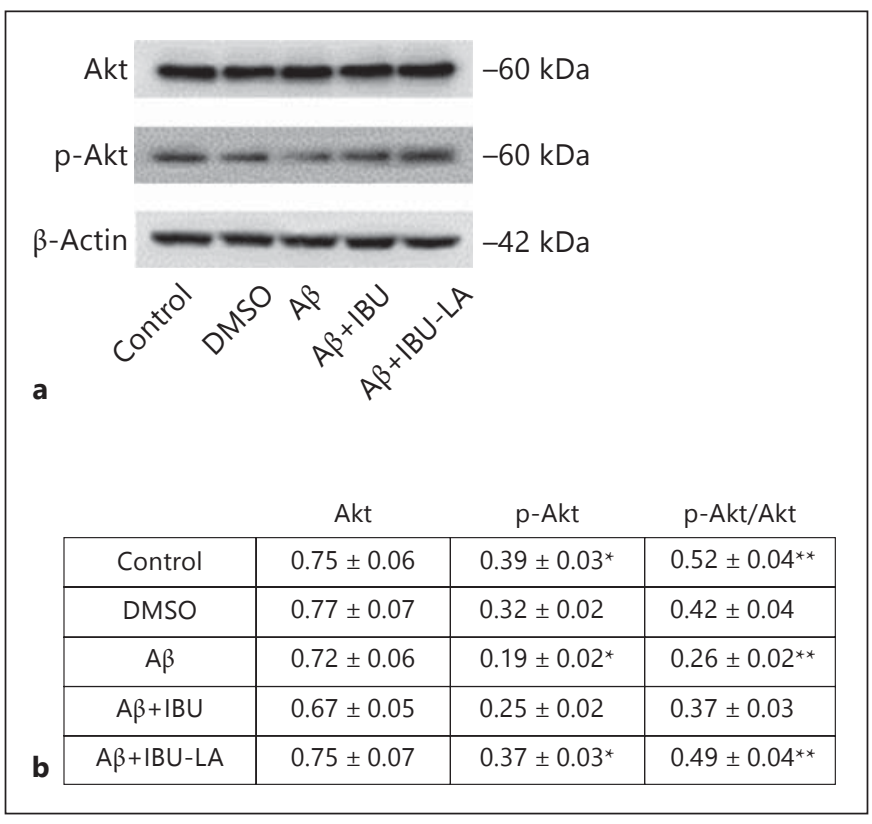

Fig. 3. a Expression of Akt and p-Akt in rat cerebral cortex in different experimental conditions. Western blotting is the most representative out of three different consistent experiments. As shown, samples were normalized by incubating membranes in the presence of $\beta$-actin monoclonal antibody. $\mathbf{b}$ Densitometric analysis performed on three different consistent experiments $( \pm S D)$. ${ }^{\star} \mathrm{A} \beta \mathrm{p}$-Akt vs. control p-Akt $\mathrm{p}<0.05\left(\mathrm{p}=3.4 \times 10^{-2}\right) ;{ }^{\star} \mathrm{A} \beta \mathrm{p}$-Akt vs. A $\beta+$ IBU-LA p-Akt $\mathrm{p}<0.05\left(\mathrm{p}=3.1 \times 10^{-2}\right) ;{ }^{\star \star} \mathrm{A} \beta \mathrm{p}-\mathrm{Akt} / \mathrm{Akt}$ vs. control p-Akt/Akt $\mathrm{p}<0.05\left(\mathrm{p}=1.7 \times 10^{-2}\right) ;{ }^{* *} \mathrm{~A} \beta \mathrm{p}$-Akt/Akt vs. A $\beta+$ IBU-LA p-Akt/Akt $\mathrm{p}<0.05\left(\mathrm{p}=1.4 \times 10^{-2}\right)$.

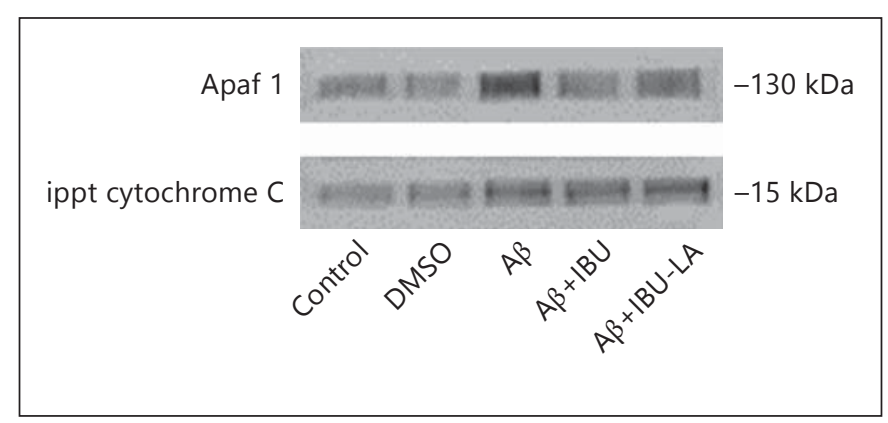

Fig. 5. Co-immunoprecipitation of cytochrome C and Apaf 1. Immunoprecipitated cytochrome $\mathrm{c}$ was probed against rabbit Apaf 1 polyclonal antibody and reprobed against mouse cytochrome $\mathrm{C}$ monoclonal antibody. Note that cytochrome C/Apaf 1 complex is present mainly in $\mathrm{A} \beta(1-40)$-injected cerebral cortex.

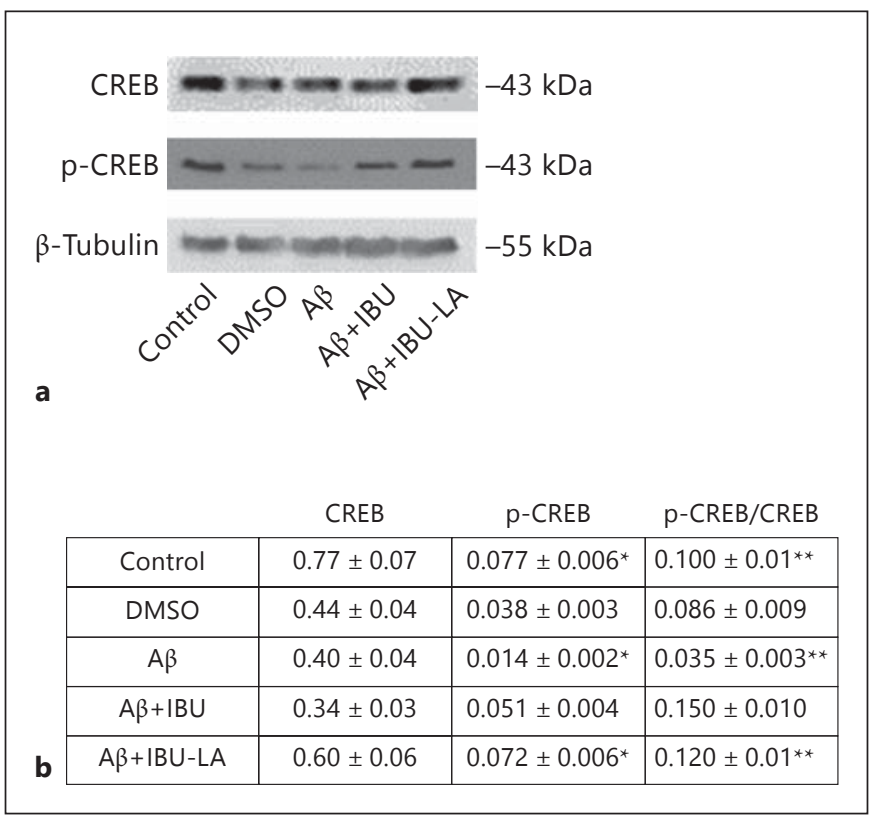

Fig. 4. a Expression of CREB and p-CREB in rat cerebral cortex in different experimental conditions. Western blotting is the most representative out of three different consistent experiments. As shown, samples were normalized by incubating membranes in the presence of $\beta$-tubulin monoclonal antibody. b Densitometric analysis performed on three different consistent experiments $( \pm S D)$. ${ }^{\star} \mathrm{A} \beta \mathrm{p}$-CREB vs. control $\mathrm{p}$-CREB $\mathrm{p}<0.05\left(\mathrm{p}=3.7 \times 10^{-2}\right) ; \mathrm{A} \beta \mathrm{p}-$ CREB vs. $\mathrm{A} \beta+\mathrm{IBU}-\mathrm{LA} \mathrm{p}-\mathrm{CREB} \mathrm{p}<0.05\left(\mathrm{p}=4.0 \times 10^{-2}\right)$; ${ }^{* *} \mathrm{~A} \beta \mathrm{p}-$ CREB/CREB vs. control $\mathrm{p}$-CREB/CREB $\mathrm{p}<0.05\left(\mathrm{p}=1.3 \times 10^{-2}\right)$; ** $\mathrm{A} \beta$ p-CREB/CREB vs. $\mathrm{A} \beta+\mathrm{IBU}-\mathrm{LA} \mathrm{p}-\mathrm{CREB} / \mathrm{CREB} \mathrm{p}<0.05$ $\left(\mathrm{p}=1.7 \times 10^{-2}\right)$.

IBU-LA is able to reach the brain unchanged ( $\mathrm{t}^{1 / 2} \mathrm{rat}$ plasma about $60 \mathrm{~min}$ ) and after passing through the BBB is rapidly hydrolyzed ( $\mathrm{t}^{1} / 2$ rat brain about $15 \mathrm{~min}$ ) (fig. 8 ) to give the parent drugs as outlined in figure 9.

\section{Discussion}

$\mathrm{AD}$ is the most common chronic neurodegenerative disorder in the elderly, characterized by neuronal degeneration provoked by $A \beta$ aggregates precipitation and tau protein hyperphosphorylation along with an increase in inflammatory and oxidative stress. In fact, $A \beta$ deposition within the cerebral cortices, activating reactive oxygen species and reactive nitrogen species production, leads to a wide inflammatory status in the brain of AD patients [35]. Previous studies have already demonstrated decreased Ngb levels with age in several human and rat brain regions, suggesting a possible relation between $\mathrm{Ngb}$ deficiency and 


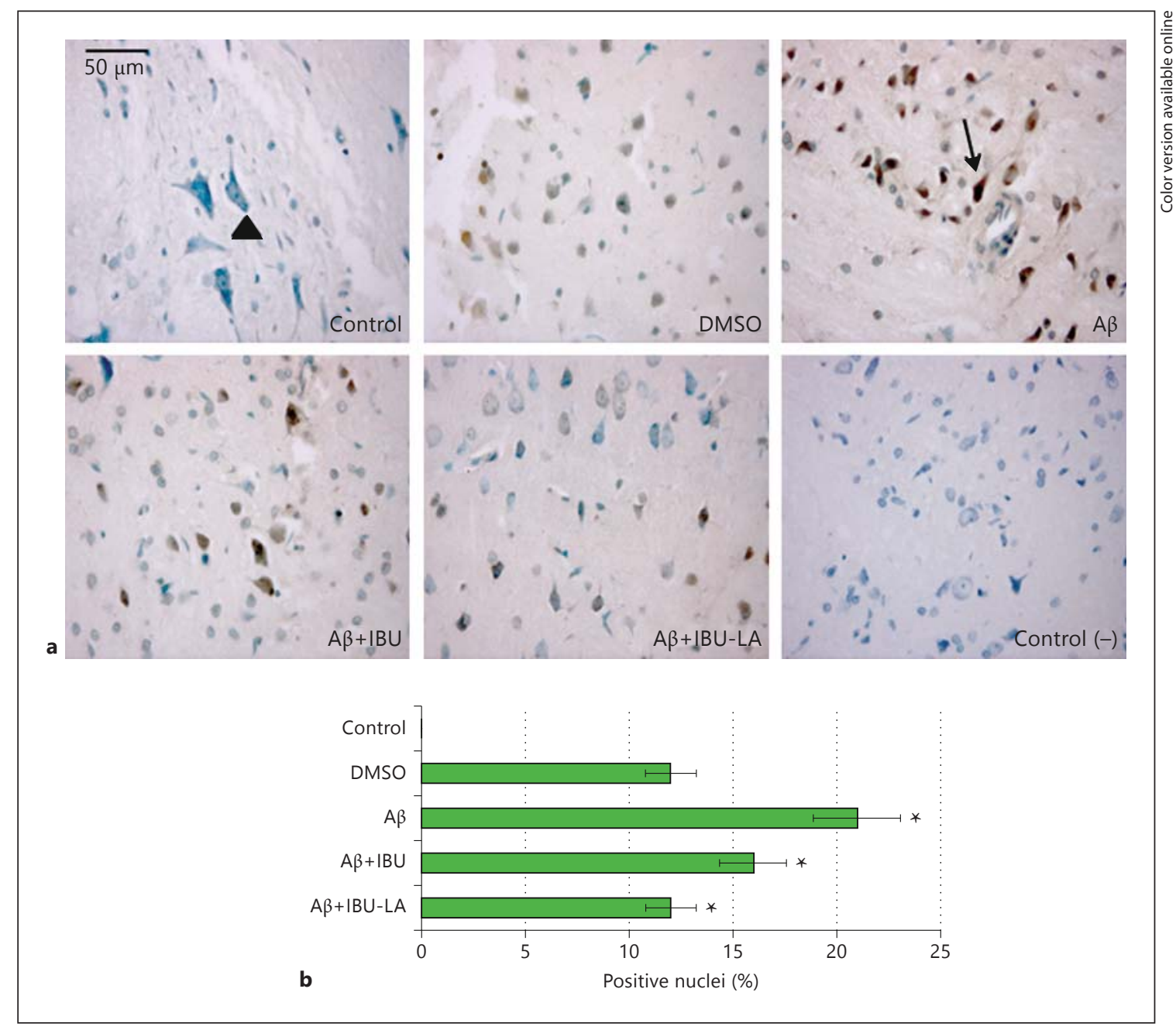

Fig. 6. a TUNEL analysis of rat cerebral cortex in different experimental conditions. The presence of DNA fragmentation was quantified by direct visual counting of brown counterstained nuclei. $\times 40$. Arrows indicate positive nuclei; arrow head indicates negative cells. b Graphical representation of TUNEL analysis. Five slides were examined per sample. Apoptotic cells were counted out of a total of 100 cells. Percentage values represented in the graph are means \pm SD. $n=3$ for all groups. ${ }^{*} A \beta \%$-positive nuclei vs. $\mathrm{A} \beta+\mathrm{IBU}$-LA-positive nuclei $\mathrm{p}<0.01\left(\mathrm{p}=2.1 \times 10^{-4}\right)$; ${ }^{\star} \mathrm{A} \beta \%$-positive nuclei vs. $\mathrm{A} \beta+\mathrm{IBU}$-positive nuclei $\mathrm{p}<0.05\left(\mathrm{p}=3.3 \times 10^{-2}\right)$; * $\mathrm{A} \beta+\mathrm{IBU} \%$-positive nuclei vs. $\mathrm{A} \beta+\mathrm{IBU}-\mathrm{LA}$-positive nuclei $\mathrm{p}<0.05\left(\mathrm{p}=3.8 \times 10^{-2}\right)$. age-related neurodegeneration [9, 10]. Moreover, Ngb promotes survival of neurons in vitro and protects the brain from damage by both $\mathrm{AD}$ and stroke [36]. Basing on this knowledge, the aim of our work was to evaluate the IBU-LA-mediated effect on neuroglobin and downstream signaling events, focusing on the neuroprotective and antiapoptotic role played by such molecules in $A \beta$-infused rat cerebral cortex, as a model of AD.

First the validity of our model was checked by morphological analysis along with $A \beta(1-40)$ immunohistochemistry, revealing an altered morphology with few nerve connections and $A \beta(1-40)$ expression within the blood vessels in the $A \beta$-infused sample and thus confirming $\mathrm{AD}$ induction.

Since Chen et al. [13] have previously demonstrated that the level of Ngb was significantly reduced in different mice AD model, the first step of our protocol was to estimate if IBU-LA administration could affect Ngb production in the $\mathrm{AD}$ model. Interestingly, our results show a deep decrease in $\mathrm{Ngb}$ level in the $\mathrm{A} \beta$-infused sample and mostly a significant restoration in the $A \beta+I B U$ - and $A \beta+I B U-L A-t r e a t e d ~ s a m p l e s$ when compared with the control sample, suggesting that both IBU and IBU-LA could improve neuronal protection through Ngb activa- 


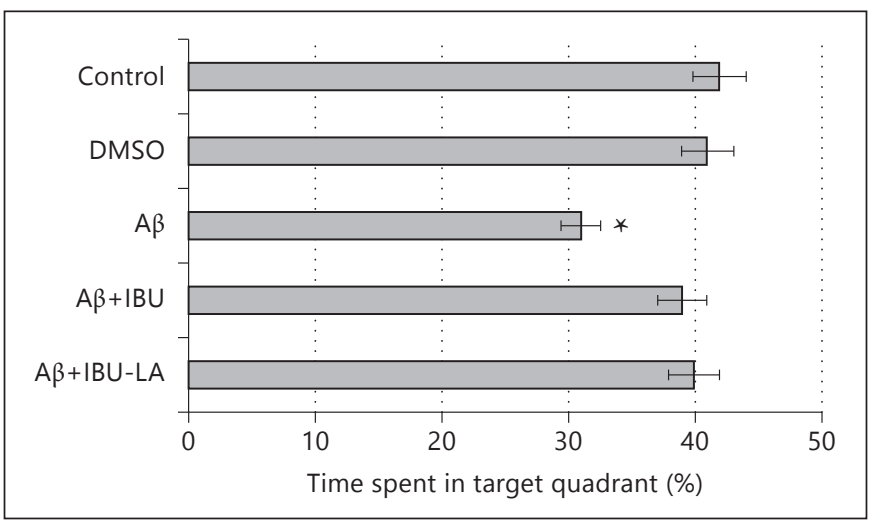

Fig. 7. Probe test performance in different experimental conditions in a Morris Water Maze $24 \mathrm{~h}$ after training. Percentage time spent in the target quadrant are means \pm SD. $n=7$ rats for all groups. ${ }^{\star} \mathrm{A} \beta \%$ time spent in target quadrant vs. all groups $\%$ time spent in target quadrant $\mathrm{p}<0.05\left(\mathrm{p}=3.7 \times 10^{-2}\right)$.

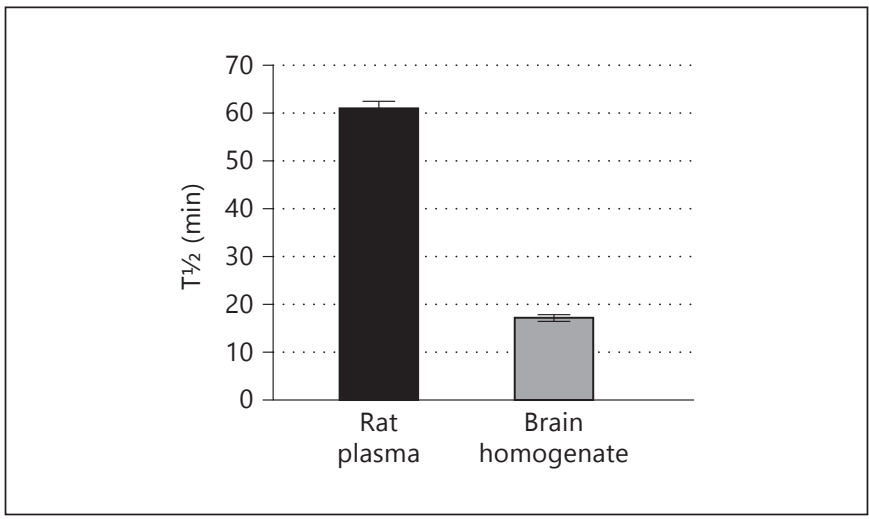

Fig. 8. Pharmacokinetic data of codrug in rat plasma and brain.

Fig. 9. Schematization of codrug biocon-

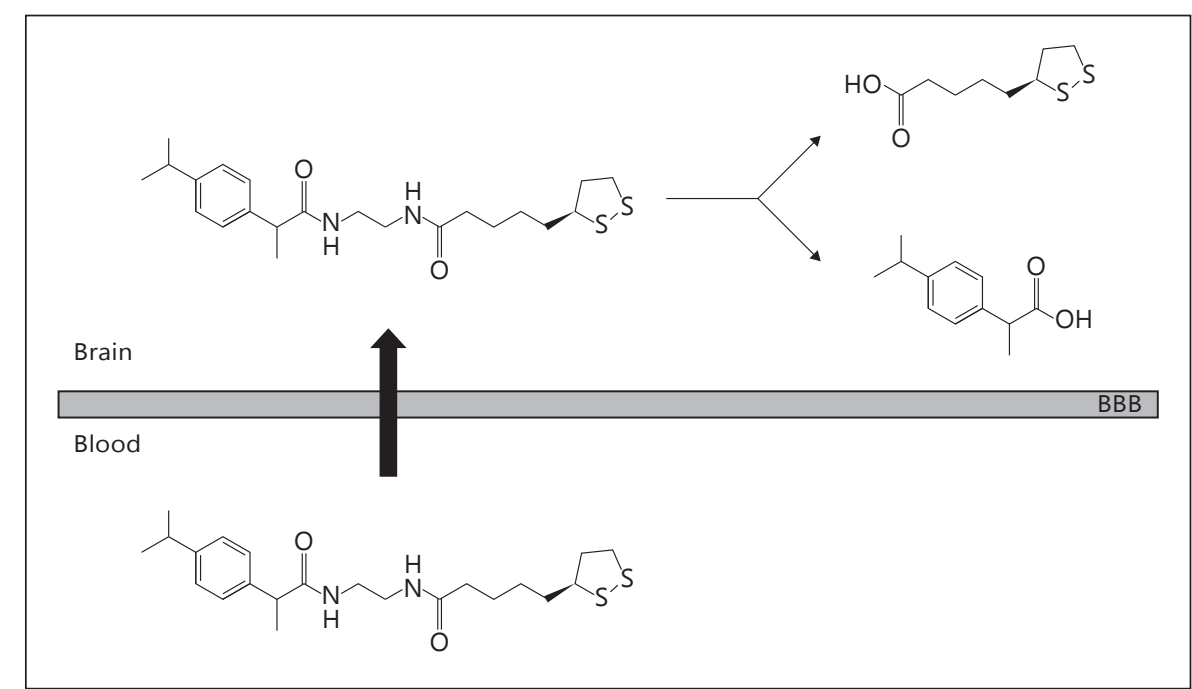
version in rat brain.

tion. Furthermore, as it is well known that Ngb directly promotes Akt phosphorylation, we then investigated the Akt expression, finding that although the inactive form does not show changes in expression, the phosphorylated form ( $p$-Akt) appears higher in the A $\beta+I B U-L A-$ treated sample than in the $A \beta$-infused and $A \beta+I B U$ treated samples, confirming this evidence in our experimental model as well. Given that CREB is a regulatory target for the protein kinase Akt [34], CREB and the phosphorylated/activated form of CREB (p-CREB) expression were studied showing a trend parallel to the $\mathrm{p}$ Akt/Akt ratio.
The protective role played by Ngb can arise from the regulation exerted on the apoptotic mitochondrial pathway [37]. In particular, Ngb seems to bind cytochrome C on Lys 72 and 25 residues [38], the same amino acidic residues involved in cytochrome C/Apaf 1 interaction [39]. Thus, based on these data, we have lastly considered the apoptotic event occurrence through both cytochrome C/Apaf 1 immunocomplex formation and TUNEL analyses. In fact, the formation of cytochrome C/Apaf 1 complex is revealed in the $A \beta$-infused sample. Moreover, a significant higher apopototic nuclei percentage in $A \beta$ infused sample than in the A $\beta+$ IBU-LA-treated sample is 
shown, while the percent decrease of apoptotic nuclei in the $A \beta+I B U$-treated sample is not statistically significant with respect to the $A \beta$-infused sample. This evidence supports the hypothesis of the role Ngb plays in the regulation of the intrinsic apoptotic pathway.

This study also evaluated the stability of this new codrug in peripheral and central enzymatic degradation. The results obtained have shown that our codrug is able to reach the brain unchanged ( $\mathrm{t}^{1 / 2}$ rat plasma about $\left.60 \mathrm{~min}\right)$ and after passing through the $\mathrm{BBB}$ was rapidly hydrolyzed $(\mathrm{t} 1 / 2 \mathrm{rat}$ brain about $15 \mathrm{~min}$ ) to give the parent drugs.

IBU-LA was also extremely stable in human serum, with half-lives exceeding $115 \mathrm{~min}$, indicating a high resistance to peripheral enzymatic degradation (data not shown) [24].

The conjugate IBU-LA has also displayed free radical scavenging activity and might allow targeted delivery of LA and IBU to neurons where cellular oxidative stress and inflammation seem related to AD. In this study, whether IBU-LA improves learning and memory in an infused $\mathrm{AD}$ rat model has also been investigated. As expected, probe test performance shows an increased spatial reference memory at the end of learning or memory

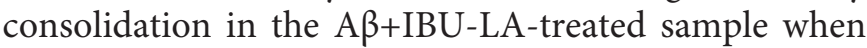
compared with $A \beta$ rats, which show an altered ability to localize a platform in the same position, even if no significant differences can be identified between the $A \beta+$ IBU-LA and A $\beta+$ IBU samples.

Even if IBU alone and IBU-LA seem to have similar effects in terms of $\mathrm{Ngb}$ expression level and behavioral results, the molecule synthetized in our laboratory could represent a new useful drug owing to its ability to cross the $\mathrm{BBB}$ and thus enhance brain availability and allowing targeted delivery of IBU and LA directly to the neurons where cellular stress and inflammation are associated with $\operatorname{AD}[22,40]$.

IBU-LA administration has the capability to maintain a high Ngb level in an $\mathrm{AD}$ model, allowing Ngb to perform either its neuroprotective role, through p-Akt and p-CREB recruitment, and its antiapoptotic effect, affecting the mitochondrial apoptotic pathway, and represents a valid tool in therapeutic strategy to counteract the progression of $\mathrm{AD}$.

\section{Acknowledgements}

This work was supported by MIUR 2011 60\% grants to Prof. A. Cataldi and Prof. A. Di Stefano.

\section{References}

>1 Selkoe DJ: Alzheimer's disease: a central role for amyloid. J Neuropathol Exp Neurol 1994; 53:438-447.

-2 Parihar MS, Hemnani T: Alzheimer's disease pathogenesis and therapeutic interventions. J Clin Neurosci 2004;11:456-467.

-3 Richardson RL, Kim EM, Shephard RA, Gardiner T, Cleary J, O'Hare E: Behavioural and histopathological analyses of ibuprofen treatment on the effect of aggregated Abeta(1-42) injections in the rat. Brain Res 2002;954:1-10.

-4 Cerpa W, Dinamarca MC, Inestrosa NC: Structure-function implications in Alzheimer's disease: effect of Abeta oligomers at central synapses. Curr Alzheimer Res 2008;5:233243.

5 Retz W, Gsell W, Münch G, Rösler M, Riederer P: Free radicals in Alzheimer's disease. J Neural Transm Suppl 1998;54:221-236.

-6 Burmester T, Weich B, Reinhardt S, Hankeln $\mathrm{T}$ : A vertebrate globin expressed in the brain. Nature 2000;407:520-523.

7 Kelsen J,Hundahl CA, Hay-Schmidt A: Neuroglobin: endogenous neuroprotectant or maintenance of homeostasis? Stroke 2008;39:e177e178.

8 Greenberg DA, Jin K, Khan AA: Neuroglobin: an endogenous neuroprotectant. Curr Opin Pharmacol 2008;8:20-24. $\checkmark 9$ Sun Y, Jin K, Mao XO, Xie L, Peel A, Childs JT, Logvinova A, Wang X, Greenberg DA: Effect of aging on neuroglobin expression in rodent brain. Neurobiol Aging 2005;26:275-278.

10 Szymanski M, Wang R, Fallin MD, Bassett SS, Avramopoulos D: Neuroglobin and Alzheimer's dementia: genetic association and gene expression changes. Neurobiol Aging 2010; 31:1835-42.

11 Khan AA, Mao XO, Banwait S, Jin K, Greenberg DA: Neuroglobin attenuates beta-amyloid neurotoxicity in vitro and transgenic Alzheimer phenotype in vivo. Proc Natl Acad Sci USA 2007;104:19114-19119.

-12 Li RC, Pouranfar F, Lee SK, Morris MW, Wang Y, Goza, D: Neuroglobin protects PC12 cells against beta-amyloid-induced cell injury. Neurobiol Aging 2008;29:1815-1822.

$\checkmark 13$ Chen LM, Xiong YS, Kong FL, Qu M, Wang Q, Chen XQ, Wang JZ, Zhu LQ: Neuroglobin attenuates Alzheimer-like tau hyperphosphorylation by activating Akt signaling. J Neurochem 2012;120:157-164.

14 Nicholson KM, Anderson NG: The protein kinase B/Akt signalling pathway in human malignancy. Cell Signal 2002;14:381-395.
15 Andreatta CP, Nahreini P, Hanson AJ, Prasad $\mathrm{KN}$ : Regulated expression of VP16CREB in neuroblastoma cells: analysis of differentiation and apoptosis. J Neurosci Res 2004;78: 570-579.

16 Cataldi A, di Giacomo V, Rapino M, Genovesi D, Rana RA: Cyclic nucleotide response element binding protein (CREB) activation promotes survival signal in human K562 erythroleukemia cells exposed to ionising radiation/etoposide combined treatment. J Radiat Res 2006;47:113-120.

17 Cataldi A, di Giacomo V, Rapino M, Zara S, Rana RA: Ionizing radiation induces apoptotic signal through protein kinase $\mathrm{C}$ delta (delta) and survival signal through Akt and cyclicnucleotide response element-binding protein (CREB) in Jurkat T cells. Biol Bull 2009;217: 202-212.

18 Bito H, Takemoto-Kimura S: $\mathrm{Ca}(2+) / \mathrm{CREB} /$ CBP-dependent gene regulation: a shared mechanism critical in long-term synaptic plasticity and neuronal survival. Cell Calcium 2003;34:425-430.

-19 Pugazhenthi S, Wang M, Pham S, Sze CI, Eckman CB: Downregulation of CREB expression in Alzheimer's brain and in $A \beta$-treated rat hippocampal neurons. Mol Neurodegener 2011;19:60. 
20 DaRocha-Souto B, Coma M, Pérez-Nievas BG, Scotton TC, Siao M, Sánchez-Ferrer P, Hashimoto T, Fan Z, Hudry E, Barroeta I, Serenó L, Rodríguez M, Sánchez MB, Hyman BT, Gómez-Isla T: Activation of glycogen synthase kinase- 3 beta mediates $\beta$-amyloid induced neuritic damage in Alzheimer's disease. Neurobiol Dis 2012;45:425-437.

-21 Klafki HW, Staufenbiel M, Kornhuber J, Wiltfang J: Therapeutic approaches to Alzheimer's disease. Brain 2006;129:2840-2855.

22 Nordberg A: Mechanisms behind the neuroprotective actions of cholinesterase inhibitors in Alzheimer disease. Alzheimer Dis Assoc Disord 2006;20:S12-S18.

-23 Wu HM, Tzeng NS, Qian L, Wei SJ, Hu X, Chen SH, Rawls SM, Flood P, Hong JS, Lu RB: Novel neuroprotective mechanisms of memantine: increase in neurotrophic factor release from astroglia and anti-inflammation by preventing microglial activation. Neuropsychopharmacology 2009;34:2344-2357.

24 Sozio P, D’Aurizio E, Iannitelli A, Cataldi A, Zara S, Cantalamessa F, Nasuti C, Di Stefano A: Ibuprofen and lipoic acid diamides as potential codrugs with neuroprotective activity. Arch Pharm 2010;343:133-142.

25 Hirohata M, Ono K, Naiki H, Yamada M: Non-steroidal anti-inflammatory drugs have amyloidogenic effects for Alzheimer's betaamyloid fibrils in vitro. Neuropharmacology 2005;49:1088-1099.

26 Leuchtenberger S, Beher D, Weggen S: Selective modulation of Abeta- 42 production in Alzheimer's disease: non-steroidal anti-inflammatory and beyond. Curr Pharm Des 2006;12:4337-4355.
27 Miners JS, Baig S, Palmer J, Palmer LE, Kehoe PG, Love S: A $\beta$-degrading enzymes in Alzheimer's disease. Brain Pathol 2008;18:240252.

28 Weggen S, Eriksen JL, Das P, Sagi SA, Wang R, Pietrzik CU, Findlay KA, Smith TE, Murphy MP, Bulter T, Kang DE, Marquez-Sterling N, Golde TE, Koo EH: A subset of NSAIDs lower amyloidogenic Abeta42 independently of cyclooxygenase activity. Nature 2001;8: 212-216.

29 Holmquist L, Stuchbury G, Berbaum K, Muscat S, Young S, Hager K, Engel J, Munch G: Lipoic acid as a novel treatment for Alzheimer's disease and related dementias. Pharmacol Ther 2007;113:154-164.

30 Hager K, Kenklies M, McAfoose J, Engel J, Munch G: Alpha-lipoic acid as a new treatment option for Alzheimer's disease: a 48 months follow-up analysis. J Neural Transm Suppl 2007;72:189-193.

-31 Di Stefano A, Sozio P, Cerasa LS, Iannitelli A, Cataldi A, Zara S, Giorgioni G, Nasuti C: Ibuprofen and lipoic acid diamide as co-drug with neuroprotective activity: pharmacological properties and effects in beta-amyloid (1-40) infused Alzheimer's disease rat model. Int J Immunopathol Pharmacol 2010;23:589-599.

32 Morris R: Developments of a water-maze procedure for studying spatial learning in the rat. J Neurosci Methods 1982;22:47-60.

33 Dickson DW: Apoptotic mechanisms in Alzheimer neurofibrillary degeneration: cause or effect? J Clin Invest 2004;114:23-27.
4 Chong ZZ, Li F, Maiese K: Activating Akt and the brain's resources to drive cellular survival and prevent inflammatory injury. Histol Histopathol 2005;20:299-315.

35 Zara S, Di Stefano A, Nasuti C, Rapino M, Patruno A, Pesce M, Sozio P, Cerasa LS, Cataldi A: NOS-mediated morphological and molecular modifications in rats infused with $A \beta(1-$ 40 ), as a model of Alzheimer's disease, in response to a new lipophilic molecular combination codrug-1. Exp Gerontol 2011;46:273-281.

36 Brittain T, Skommer J, Raychaudhuri S, Birch $\mathrm{N}$ : An antiapoptotic neuroprotective role for neuroglobin. Int J Mol Sci 2010;11:2306-2321.

37 Fago A, Mathews AJ, Brittain T: A role for neuroglobin: resetting the trigger level for apoptosis in neuronal and retinal cells. IUBMB Life 2008;60:398-401.

-38 Raychaudhuri S, Skommer J, Henty K, Birch $\mathrm{N}$, Brittain T: Neuroglobin protects nerve cells from apoptosis by inhibiting the intrinsic pathway of cell death. Apoptosis 2010;15:401411.

39 Chertkova RV, Sharonov GV, Feofanov AV, Bocharova OV, Latypov RF, Chernyak BV, Arseniev AS, Dolgikh DA, Kirpichnikov MP: Proapoptotic activity of cytochrome $\mathrm{C}$ in living cells: effect of K72 substitutions and species differences. Mol Cell Biochem 2008;314: 85-93.

40 Chen Q, Gong T, Liu J, Wang X, Fu H, Zhang $\mathrm{Z}$ : Synthesis, in vitro and in vivo characterization of glycosyl derivatives of ibuprofen as novel prodrugs for brain drug delivery. J Drug Target 2009;17:318-328. 